\title{
Printed Square Quadrifilar Helix Antenna (QHA) for GPS Receiver
}

\author{
Wang-Ik Son ${ }^{\# 1}$, Won-Gyu Lim ${ }^{\# 2}$, Moon-Que Lee ${ }^{* 3}$, Sang-Bo Min ${ }^{\circledR 4}$, Jong-Won $\mathrm{Yu}^{\# 5}$ \\ \# Korea Advanced Institute of Science and Technology (KAIST), Deajeon, Korea \\ wangik@kaist.ac.kr \\ ${ }^{2}$ limwongyu@kaist.ac.kr \\ ${ }^{5}$ drjwyu@ee.kaist.ac.kr \\ * The University of Seoul (UOS), Seoul, Korea \\ 3mqlee@uos.ac.kr \\ ${ }^{\circledR}$ Actenna Corporation, Seoul, Korea \\ ${ }^{4}$ sam911@paran.com
}

\begin{abstract}
A new printed square quadrifilar helix antenna (QHA) for circular polarization (CP) is proposed and experimentally investigated for the application as a GPS receiving antenna in frequency range of about $1.575 \mathrm{GHz}$. To increase the input impedance of QHA, we use the folded inverted-F antenna as a helix. Experiment results show that the proposed antenna has a 3-dB beamwidth of more than $120^{\circ}$ and a front-to-back ratio of more than $15 \mathrm{~dB}$. Also, the proposed antenna shows the peak gain of $\mathbf{- 2 . 5} \mathrm{dBic}$ and the axial ratio under $0.5 \mathrm{~dB}$ in wanted frequency band.
\end{abstract}

\section{INTRODUCTION}

Global Positioning System (GPS) is a satellited-based navigation system to provide instantaneous 3D position, velocity and time information almost anywhere on or above the surface of the earth at any time [1]. In GPS system, the design of the antenna is one of the most important aspects for receiving signals from satellites exactly. The antenna is expected to cover as many satellites as possible over the hemisphere, with high rejection of the multipath and cross polarized signals.

Circularly polarized (CP) patch antennas have been widely used for GPS applications due to its broad beamwidth and good circular polarization. But a CP patch antenna has a high backward radiation as the size of ground plane is reduced [2] This means that the antenna has lesser forward radiation and receives more noise from the bottom. So, the $\mathrm{C} / \mathrm{N}$ of the antenna is reduced.

The quadrifilar helix antenna (QHA) invented by Gerst [3], [4] consists of four tape helices equally spaced circumferentially on a cylinder and fed with equal amplitude signals with relative phases of $0^{\circ}, 90^{\circ}, 180^{\circ}$, and $270^{\circ}$. This antenna is suitable for GPS receiver antenna because of its broad beamwidth and broad circularly polarized beamwidth. Also it has a low backward radiation when the size of ground is reduced. Recently, the size of the QHA for GPS is reduced more and more for using in handheld mobiles [5], [6]. As the size of QHA gets smaller, the mutual coupling between the helix is increased. So, the input impedance is smaller and the radiation efficiency is decreased [7].

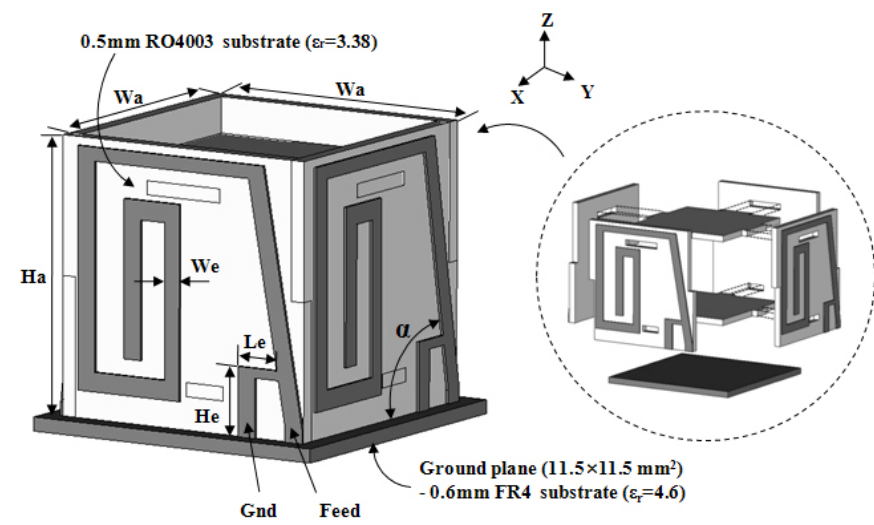

Fig. 1 The geometry of the proposed antenna (Prototype: $\mathrm{W}_{\mathrm{a}}=10 \mathrm{~mm}$, $\left.\mathrm{H}_{\mathrm{a}}=10 \mathrm{~mm}, \mathrm{~W}_{\mathrm{e}}=0.7 \mathrm{~mm}, \mathrm{~L}_{\mathrm{e}}=1.5 \mathrm{~mm}, \mathrm{H}_{\mathrm{e}}=2.5 \mathrm{~mm}, \alpha=80^{\circ}\right)$

In this paper, we proposed a compact printed square QHA for GPS application. To increase the input impedance of QHA, we used the folded inverted-F antenna as a helix. Also, the radiation efficiency is increased.

\section{DESIGN OF PRINTED SQUARE QHA}

Fig. 1 shows the geometry of the proposed compact square printed QHA. The antenna is mounted above a grounded FR4 substrate (thickness $0.6 \mathrm{~mm}$, relative permittivity 4.6 , and size $11.5 \times 11.5 \mathrm{~mm}^{2}$ ). In a grounded substrate, the feeding network is implemented to produce four equal amplitude signals with relative phases of $0^{\circ}, 90^{\circ}, 180^{\circ}$, and $270^{\circ}$ to generate circularly polarized waves. Each inverted-F helix of QHA, printed on a RO4003 substrate (thickness $0.5 \mathrm{~mm}$, relative permittivity 3.38), is wound by oneself. Each helix has a length of $39 \mathrm{~mm}$, width $\left(\mathrm{W}_{\mathrm{e}}\right)$ of $0.7 \mathrm{~mm}$ and pitch angle $(\alpha)$ of $80^{\circ}$ to resonate in GPS frequency band. Four printed helices are combined into a square QHA using two fixing plates. The width $\left(\mathrm{W}_{\mathrm{a}}\right)$ of the combined antenna is $10 \mathrm{~mm}$ and the height $\left(\mathrm{H}_{\mathrm{a}}\right)$ is also $10 \mathrm{~mm}$. To increase input impedance, there is a shorted matching line in each helix, which is used as an inverted-F antenna. The distance between a helix and a match- 


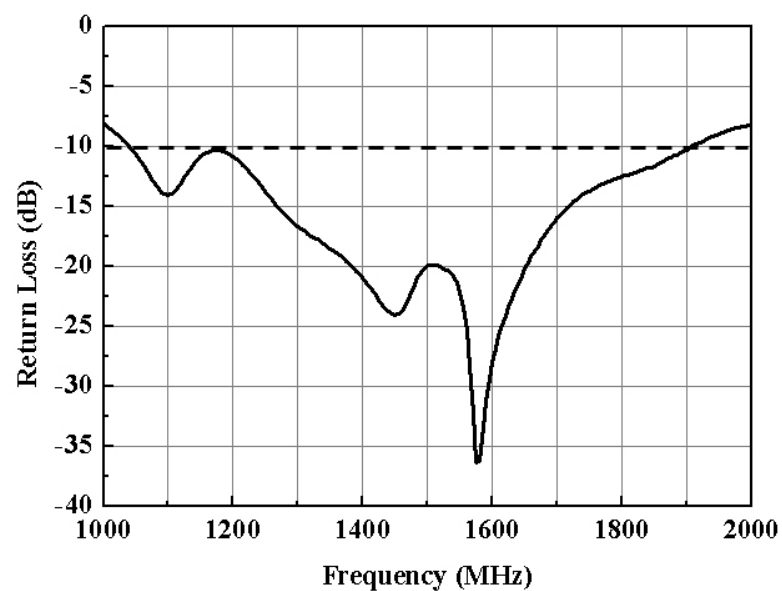

Fig. 2 Measured return loss for the proposed antenna

ing line $\left(\mathrm{L}_{\mathrm{e}}\right)$ and the height of the matching line $\left(\mathrm{H}_{\mathrm{e}}\right)$ are chosen to be $1.5 \mathrm{~mm}, 2.5 \mathrm{~mm}$ for good impedance match, respectively.

\section{EXPERIMENTAL RESULTS}

Fig. 2 shows the measured return loss. A very wide impedance bandwidth of about $700 \mathrm{MHz}$ centered at about $1.575 \mathrm{GHz}$ is observed, which is due to the wide bandwidth characteristic of the feed network.

In QHA, reducing the size of the antenna causes a decrement of the input impedance of each helix since the mutual coupling between helices is increased. If the input impedance is decreased, the radiation efficiency is decreased and the impedance mismatch is generated between each helix and feed network. Hence, the folded inverted-F antenna as a helix is adopted to increase the input impedance. When the shorted line is added to the helix, the inductance of the shorted line is connected to the original impedance of the helix in parallel. Therefore, the input impedance is increased when the length of the shorted line is increased. In Fig. 3(a), we present the real part of the measured input impedance and the corresponding imaginary part in Fig. 3(b). Without the shorted line, the input impedance is measured as 9.27-j37.329 $\Omega$. When the height $\left(\mathrm{H}_{\mathrm{e}}\right)$ of the shorted line is increased, both real and imaginary part of input impedance is also increased as shown in Fig. 3. The measured input impedance corresponding to the value of $\mathrm{H}_{\mathrm{e}}$ is given in Table I. For good impedance matching between the input of each helix and the output of a feed network, we choose the height $\left(\mathrm{H}_{\mathrm{e}}\right)$ of shorted line as $2.5 \mathrm{~mm}$ in the proposed antenna.

The measured peak gain is about $-2.5 \mathrm{dBic}$ with a radiation efficiency of $30 \%$ at center frequency of $1.575 \mathrm{GHz}$ as shown in Fig. 4. Also, since the frequency band of GPS L1 (1563.42 1587.42) is located in 3-dB gain bandwidth, the proposed antenna provides stable gain properties. The $3-\mathrm{dB}$ gain bandwidth is about $100 \mathrm{MHz}$.

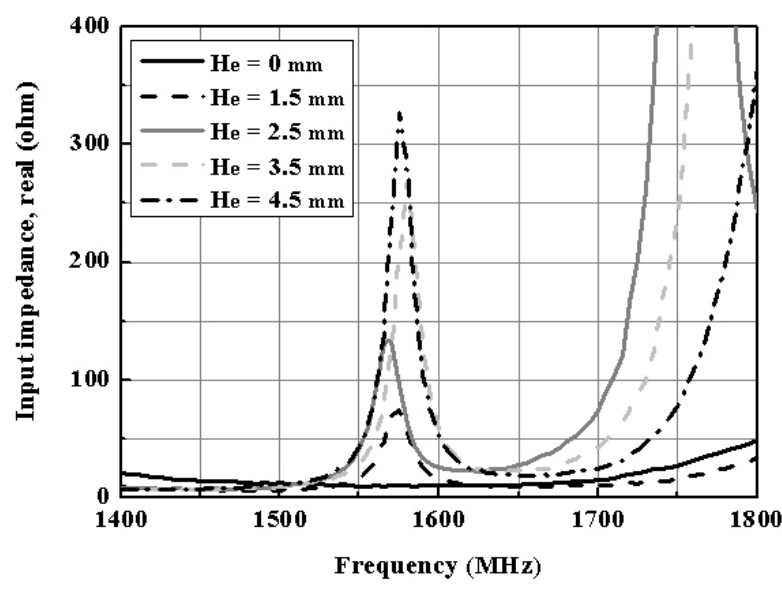

(a)

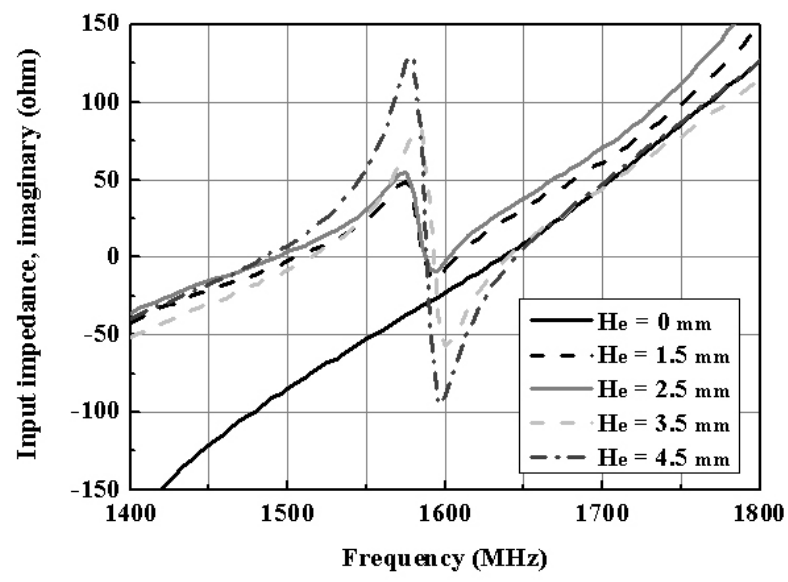

(b)

Fig. 3 Measured input impedance of each helix (a) real part (b) imaginary part

TABLE I

MEASURED INPUT IMPEDANCE

\begin{tabular}{|c|c|}
\hline $\mathbf{H}_{\mathbf{e}} \mathbf{( m m )}$ & Measured input impedance $(\mathbf{\Omega})$ \\
\hline 0 & $9.27-\mathrm{j} 37.33$ \\
\hline 1.5 & $73.91+\mathrm{j} 5.90$ \\
\hline 2.5 & $93.59+\mathrm{j} 8.54$ \\
\hline 3.5 & $208.04+\mathrm{j} 70.12$ \\
\hline 4.5 & $327.03+\mathrm{j} 126.74$ \\
\hline
\end{tabular}

The measured axial ratio is shown in Fig. 4. The proposed antenna has a good CP performance because the axial ratio is under $0.5 \mathrm{~dB}$ at all frequency in GPS L1 band. The axial ratio radiation pattern is also measured at $1.575 \mathrm{GHz}$ in Fig. 5 . Because the proposed antenna radiates a good $\mathrm{CP}$ waves through forward direction and $3-\mathrm{dB}$ axial ratio beamwidth is about $140^{\circ}$, the antenna rejects unwanted cross polarized and multipath signals effectively. 


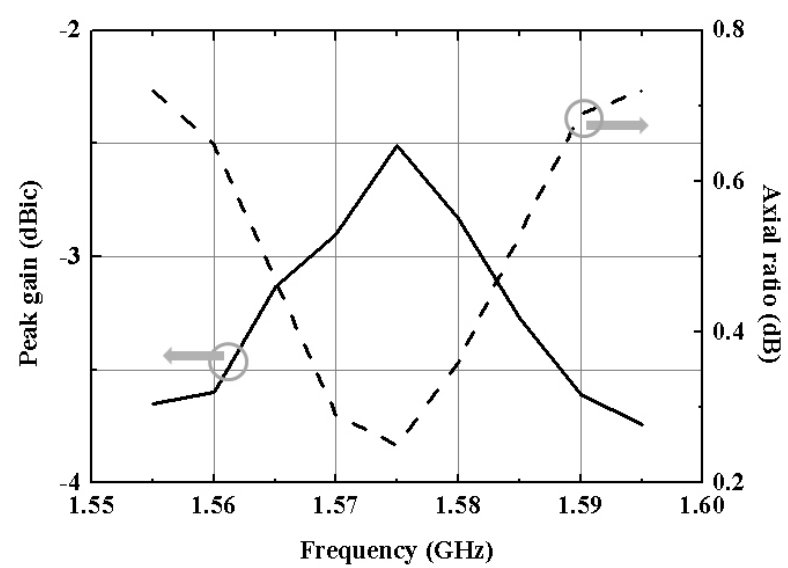

Fig. 4 Measured peak gain and axial ratio

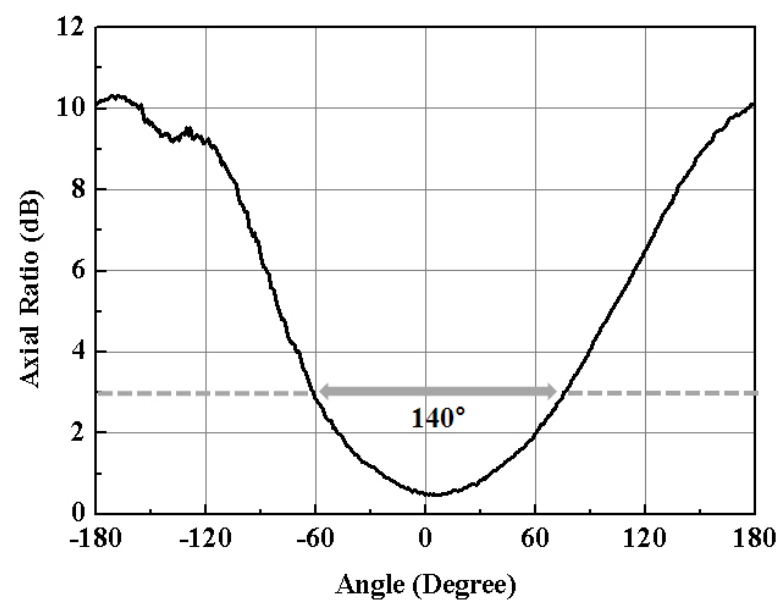

Fig. 5 Measured axial ratio radiation pattern

Fig. 6 shows the measured radiation pattern of the proposed antenna at $1.575 \mathrm{GHz}$. In Fig. 6(a), the HPBW (Half Power Beam Width) of the X-Z plane is about $140^{\circ}$ and that of the $\mathrm{Y}-\mathrm{Z}$ is about $120^{\circ}$ in Fig. 6(b). Because the antenna has a broad beamwidth about $120^{\circ}$, the antenna covers as many as satellites over the hemisphere. The front-to-back ratio is about $15 \mathrm{~dB}$, so the antenna rejects the unwanted signal from the bottom of the antenna and the device.

The implemented proposed antenna is shown in Fig. 7. A field test for the proposed antenna was conducted. Fig. 8 shows the locations of satellites which were observed at KAIST, in Daejeon, South Korea in September 15th 2007, 5:52 pm. The center point is the zenith of an observer and the outer circle indicates the horizon. The proposed antenna receives a signal from satellites $4,2,13,17,10,12,23,5$ which corresponds to $\mathrm{C} / \mathrm{N}$ of $42 \mathrm{~dB}, 43 \mathrm{~dB}, 43 \mathrm{~dB}, 42 \mathrm{~dB}, 44$ $\mathrm{dB}, 40 \mathrm{~dB}, 40 \mathrm{~dB}, 38 \mathrm{~dB}$ as you seen in Fig. 9. According to the field test, the radiation pattern coverage of the proposed antenna allows the GPS receiver to track satellites at very low elevation angles.

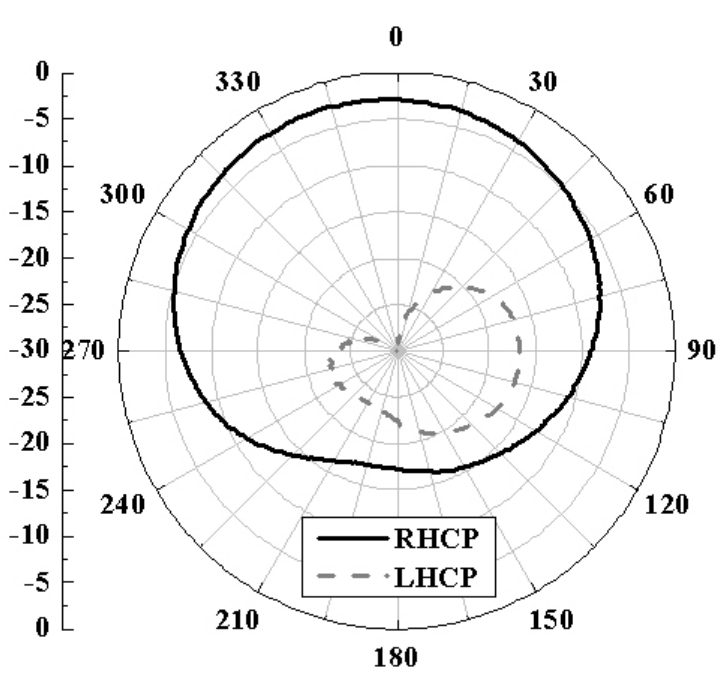

(a)

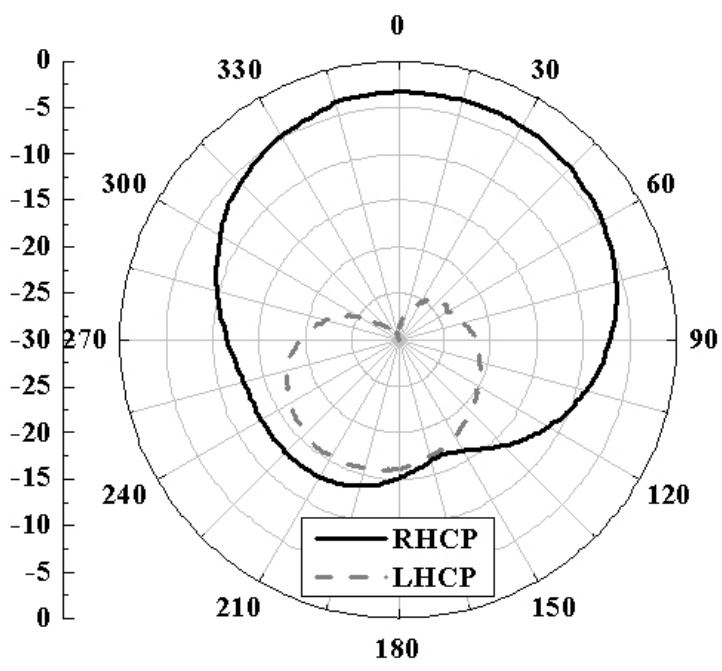

(b)

Fig. 6 Measured radiation pattern (a) X-Z plane (b) Y-Z plane

\section{CONCLUSIONS}

A new printed square quadrifilar helix antenna for GPS receiver has been presented and tested. The experimental results show that the input impedance is successfully increased by using an inverted-F antenna as a helix. Also, the proposed antenna has a good circularly polarized radiation performance. The proposed antenna can be used a promising candidate for many applications in GPS. 


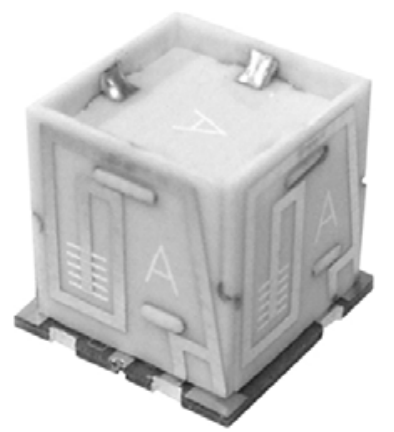

Fig. 7 The implemented proposed antenna

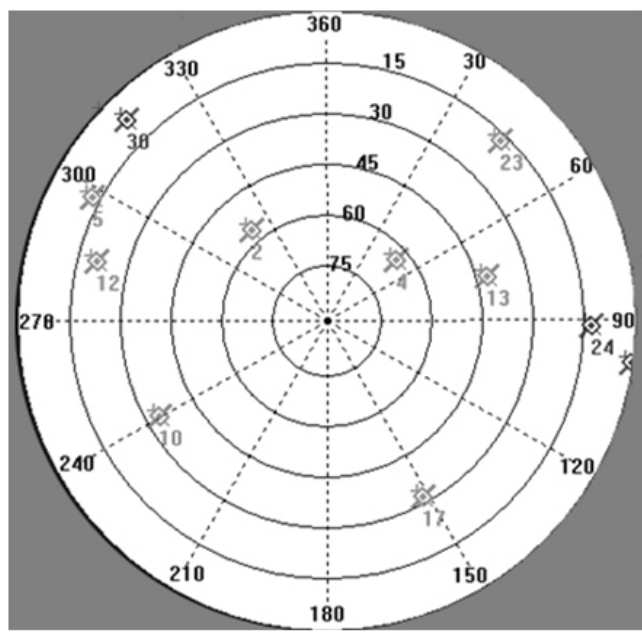

Fig. 8 The location of satellites at KAIST, Deajeon, South Korea in September 15th 2007, 5:52 pm

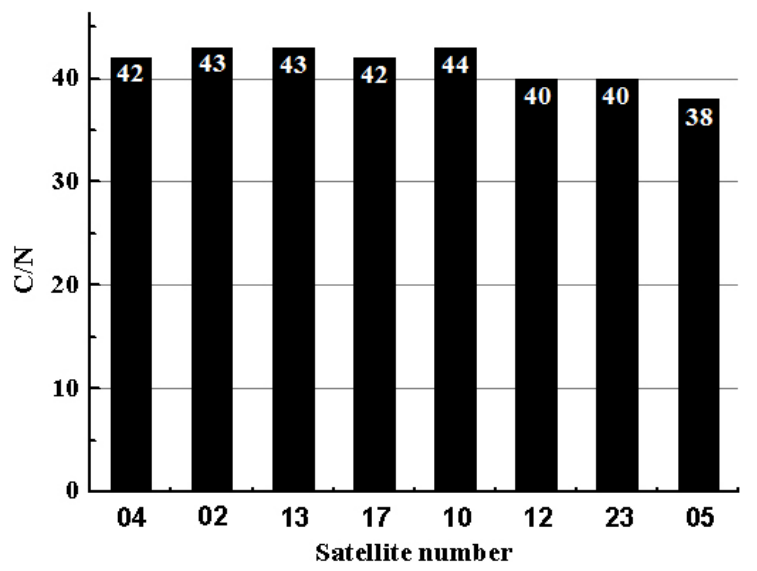

Fig. 9 Measured $\mathrm{C} / \mathrm{N}$ of the proposed antenna

\section{REFERENCES}

[1] Parkinson. B. W. and Spilker. J. R, Global Positioning System: Theory and Application, American Institute of Aeromautics and Astronautics, Washington DC, 1996.

[2] W. S. T. Rowe and R. B. Waterhouse. "Reduction of Backward Radiation for CPW Fed Aperture Stacked Patch Antennas on Small Ground Planes," IEEE Transactions on Antennas and Propagation, VOL. 51, NO. 6.

[3] C. Gerst and R. A. Worden, "Helix antennas take turn for better," Electronics, pp.100-110, August. 1966.

[4] C. Gerst, "Multifilar contrawound helical antenna study and analysis," Surveillance Technology Study and Analysis, vol. 1, Technical Report RADC-TR-67-145, May. 1967 and vol. 2, Final Report, Feb. 1967

[5] P. K. Shumaker, C. H. Ho and K. B. smith, "Printed half-wavelength quadrifilar helix antenna for GPS marine applications," Electronics Letters, Vol. 32, No. 3, Feb. 1996

[6] O. Leisten, J. C. Vardaxoglou, P. McEvoy, R. Seager and A. Wignfield, "Miniaturised dielectrically-loaded quadrifilar antenna for Global Positioning System (GPS)," Electronics Letters, Vol. 37, No. 22, October 2001.

[7] W. I. Son, W. G. Lim, M. Q. Lee, S. B. Min, and J. W. Yu, "Printed square quadrifilar spiral antenna for UHF RFID reader," in IEEE AP-S International Symposium, Honolulu, Hawaii, June. 2007, pp. 303-308 